\title{
Erratum to: Plane waves and fundamental solution in an electro-microstretch elastic solids
}

\author{
Saurav Sharma · Kunal Sharma • Raj Rani Bhargava
}

Published online: 9 May 2014

(C) African Mathematical Union and Springer-Verlag Berlin Heidelberg 2014

\section{Erratum to: Afr. Mat. DOI 10.1007/s13370-013-0161-7}

Unfortunately, one of the co-author's affiliation was incorrectly published in the original publication. The correct affiliation is given below:

K. Sharma

Department of Mechanical Engineering, NIT Kurukshetra, Haryana, India e-mail: kunal_nit90@rediffmail.com

The online version of the original article can be found under doi:10.1007/s13370-013-0161-7.

\section{S. Sharma $(\bowtie)$}

Department of Instrumentation, Kurukshetra University, Kurukshetra, Haryana, India e-mail: sauravkuk@gmail.com

K. Sharma

Department of Mechanical Engineering, NIT Kurukshetra, Haryana, India e-mail: kunal_nit90@rediffmail.com

R. R. Bhargava

Department of Mathematics, IIT Roorkee, Roorkee 247667, India

e-mail: rajrbfma@iitr.ernet.in 